\title{
The exact place of PCR and chest CT in screening, staging, and diagnosis of Covid-19: A meta-analysis
}

\section{Fatemeh Khatami}

Urology research Center, Tehran University of Medical Sciences, Tehran, Iran

\section{Mohammad Saatchi}

Department of Epidemiology and Biostatistics, School of Public Health, Tehran University of Medical

Sciences, Tehran, Iran

\section{Seyed Saeed Tamehri Zadeh}

Urology research Center, Tehran University of Medical Sciences, Tehran, Iran

\section{Zahra Sadat Aghamir}

Faculty of Dentistry, Tehran University of Medical Sciences, Tehran, Iran

\section{Alireza Namazi Shabestari}

Department of Geriatric Medicine, School of Medicine, Tehran University of Medical Sciences, Tehran, Iran

\section{Seyed Mohammad Kazem Aghamir ( $\nabla$ mkaghamir@tums.ac.ir)}

Urology research Center, Tehran University of Medical Sciences, Tehran, Iran

\section{Systematic Review}

Keywords: COVID-19, diagnosis, chest CT, RT-PCR, sensitivity, specificity

Posted Date: June 2nd, 2020

DOI: https://doi.org/10.21203/rs.3.rs-32961/v1

License: (c) (1) This work is licensed under a Creative Commons Attribution 4.0 International License. Read Full License

Version of Record: A version of this preprint was published on December 28th, 2020. See the published version at https://doi.org/10.1038/s41598-020-80061-2. 


\section{Abstract}

Introduction: Nowadays there is an ongoing acute respiratory outbreak causing by the novel highly contagious coronavirus (nCoV). There are two diagnostic protocol based on chest CT scan and quantitative reverse-transcription polymerase chain reaction (RT-PCR) which their diagnostic accuracy is under the debate. We designed this meta-analysis study to determine the diagnostic value of initial chest CT scan in patients with nCoV infection in comparison with RT- PCR.

Search strategy and statistical analysis: Three main databases the PubMed (MEDLINE), Scopus, and EMBASE was systematically searched for all published literatures from January $1 \mathrm{st}, 2019$, to the 27th march 2020 with key grouping of "COVID19 virus", "2019 novel coronavirus", "Wuhan coronavirus", "2019-nCoV”, “X-Ray Computed Tomography”, “Polymerase Chain Reaction”, “Reverse Transcriptase PCR", and "PCR Reverse Transcriptase". All relevant case- series, cross-sectional, and cohort studies were selected. Data extraction was done in Excel 2007 (Microsoft Corporation, Redmond, CA) and their analysis was performed using STATA v.14.0SE (College Station, TX, USA) and RevMan 5.

Result: From first recruited 668 articles we end up to the final 47 studies, which comprised a total sample size of 4238 patients. In compare to RT-PCR, the overall sensitivity, specificity, positive predictive value, and negative predictive value of chest CT scan were $86 \%$ (95\% Cl: $83 \%-90 \%), 43 \%$ (95\% Cl: $26 \%-60 \%)$, $67 \%$ (95\% Cl: $57 \%-78 \%)$, and $84 \%$ (95\% Cl: $74 \%-$

95\%) respectively. However the RT-PCR should be repeated for three times in order to give the $99 \%$ accuracy especially in negative samples.

Conclusion: According to the acceptable sensitivity of chest CT scan, it can be employed complement to RT-PCR to diagnosis patients who are clinically suspicious for $\mathrm{nCoV}$.

\section{Introduction}

In late December of 2019, a cluster of unknown viral pneumonia patients, who later tuned out to be infected with novel coronavirus ( $\mathrm{nCoV}$ ) (the disease named COVID-19), has been reported in Wuhan City, Hubei Province, China(1). Until 11 March, over 100 countries and 120000 cases have been involved with this beta coronavirus of whom over 4000 died and its incidence is at increasing pace worldwide. Officially, World Health Organization has declared the pandemic of $\mathrm{nCoV}$, therefore, it has attracted an international interest (2).

Currently, due to non-existence of therapeutic vaccine or certain antiviral drugs, both detecting patient at an early stage and immediate patient isolation play mandatory role in fighting against $\mathrm{nCoV}(3)$. Although chest computed tomography (CT) scan has shown promising results regarding early diagnosis of COVID-19, reverse transcription polymerase chain reaction (RT- PCR) remain to be the mainstay of this viral disease's diagnosis given the sixth version of diagnosis and treatment of COVID-19 $(3,4)$; however, RT-PCR poses several limitations that reduce the sensitivity of this method and cause some patients to be 
missed (5). Actually CT and PCR are not comparable in the diagnosis of COVID-19 because CT is valuable tool in staging of disease and checking the treatment efficacy but repeating PCR test is the diagnostic tool. Recent studies have focused on chest CT of patients with COVID-19 features and they claim that initial chest CT may enable to detect the disease with higher sensitivity in comparison to RTPCR (6). Therefore, this systematic review and meta-analysis was performed to determine diagnostic accuracy of initial chest CT scan compare to RT-PCR in patients who are infected with nCoV.

\section{Materials And Methods}

\section{Inclusion criteria}

All stages of the study followed the PRISMA guideline. Inclusion criteria were having an observational epidemiological study design, clear report of the number of positive cases by PCR and chest CT, and ability to calculate accuracy indicators.. Articles that did not meet one or more of the study entry criteria were also excluded. All relevant English, Chinese and other language case-series, cross-sectional, and cohort studies were selected. Case reports were excluded and for the remaining literatures scientific validity was performed.

\section{Search strategy}

The study was run by searching all relevant literature from three main databases: MEDLINE (PubMed), Scopus, and EMBASE from January 1st , 2019, to the 27th march 2020 with words the key grouping of "COVID19 virus", "2019 novel coronavirus", "Wuhan coronavirus", "2019- nCoV”, "X-Ray Computed Tomography", "Polymerase Chain Reaction", "Reverse Transcriptase PCR", and "PCR Reverse Transcriptase" (Supplementary file 1). In order to obtain more articles and to ensure that the appropriate search is performed in the databases, the list of selected articles was also reviewed. The variables extracted from each targeted article in included the name of the first author, the year of publication of the article, the country and city of the study, the average age of the subjects, the gender, the study design, total sample size, positive tst result, negative test result, false positive, and false negative.

\section{Data Extraction and Statistical Analysis}

To reduce the selection bias, two researchers (SZA and SSTZ) screened articles separately through checking titles and abstracts. Unlikeness and disagreement were removed by the idea of the third ones (FKH). The full text of whole candidate related articles were studied in order to grouping into the included one or excluded one. Actually, included ones had data of confirmed COVID-19 patients by chest CT scan or quantitative real time polymerase chain reaction (RT- PCR). The quality assessment was performed by the Newcastle-Ottawa Scale (NOS) assessment tool. The papers that receive score more than 6 were reflected as the "high quality" one and go to the additional meta-analysis step. 
The outcomes of interest, including the diagnostic operation of CT-scan to identify covid-19 by the random effect model, were summary receiver operating characteristic (SROC) curve sensitivity and specificity. Sensitivity, indicating the capacity of index test to identify patients, considered by "Sensitivity $=\mathrm{TP} /(\mathrm{TP}+\mathrm{FN})$ ". Specificity as the examination to remove disease- free, calculated by "Specificity = TN/ $(\mathrm{FP}+\mathrm{TN})$ ". Positive Predictive Value (PPV) is probability of disease if the test is positive calculated by "Positive predictive Value = TP/ (FP + TP)". Negative Predictive Value (NPV) is probability of disease-free if the test is negative calculated by "negative predictive value $=T N /(F N+T N)$ " The Cochran's Q-test of heterogeneity at an importance amount of $5 \%$ was used to evaluate statistical heterogeneity of the researches and 12 was practical for quantitative evaluation of heterogeneity between outcomes based on the Higgins classification in which an 12 value more than $75 \%$ is pinpointing of heterogeneity. Deeks' funnel plot was used to evaluate publication bias by the "Metafunnel". Briefly, to create the funnel plot, the odds ratio was first calculated using the equations of (TP / FN)/(FP / TN) and after estimating the odds ratio logarithm, the standard error of odds ratio was calculated. Extracted data were collected in Excel 2007 (Microsoft Corporation, Redmond, CA) and analysis was done by using STATA v.14.0SE (College Station, TX, USA) and RevMan 5.

\section{Results}

In the present study, at first $668(667+1)$ articles were identified through the search of three data bases of Pubmed, Embase, and Scopus. After deleting 188 duplicate articles, the screening was done based on the titles and abstracts which lead to the 89 articles were candidate as the related ones (figure 1). After that scoring of the articles were done based on NOS screening tool and the number of article were limited to the 47 .

Finally, 47 articles with the total sample size of 4283 recruited for the final analysis. All studies were published in the first quarter of 2020. A summary of the information in these articles is shown in Table 1. With the exception of one article from the United States, all articles were from China. According to the articles, the types of studies were 23 case-series, 14 cohorts and 10 cross sectional. The forest plot result is shown in figure 2 and the quantity of False Positives (FP), False Negative (FN) and True Positives (TP), and True Negative (TN) is shown more than sensitivity, specificity, and $95 \%$ confidence Intervals (Cl) of each study. Sensitivity ranged from $25 \%$ to $100 \%$ and the specificity was estimated to vary from $19 \%$ to $70 \%$. One of the important assumptions in calculating sensitivity and specificity using the Metaprop command is to extract studies that have reported $100 \%$ sensitivity or specificity.

Table 1: Data of 47 included file in the data extraction step. 


\begin{tabular}{|c|c|c|c|c|c|c|}
\hline N. & 1st author & Country(city) & $\begin{array}{l}\text { Gender } \% \\
\text { male }\end{array}$ & $\begin{array}{r}\text { Age mean, } \\
\text { range(yr.) }\end{array}$ & Type of study & $\begin{array}{c}\text { Sample } \\
\text { size }\end{array}$ \\
\hline 1 & Adam Bernheim(1) & $\begin{array}{c}\text { United States (New } \\
\text { York) }\end{array}$ & $50 \%$ & $45,18-80$ & Case-series & 121 \\
\hline 2 & Chun Shuang Guan(7) & China (Beijing) & $47 \%$ & $42,1-86$ & Case-series & 53 \\
\hline 3 & Chunbao Xie(8) & China (Chengdu) & $58 \%$ & $33,8-62$ & Cross-sectional & 19 \\
\hline 4 & Dahai Zhao(9) & China (Anhui) & $50 \%$ & $42,27-56$ & cohort & 34 \\
\hline 5 & Dehan Liu(10) & China (Wuhan) & $\% 0$ & $32,23-40$ & Case-series & 51 \\
\hline 6 & Fang ZHENG(11) & China (Wuhan) & $56 \%$ & 3, 2-9 & Case-series & 25 \\
\hline 7 & Fengxiang Song(12) & China (shanghai) & $49 \%$ & $49,33-65$ & Case-series & 51 \\
\hline 8 & Fneg Pang(13) & China (Wuhan) & $29 \%$ & $40,25-63$ & Case-series & 21 \\
\hline 9 & Feng Kai $(14)$ & China (Shenzhen) & $33 \%$ & $8,4-14$ & Case-series & 15 \\
\hline 10 & Jasper Fuk-Woo Chan(15) & China (Hong Kong) & $50 \%$ & $46,33-66$ & Case-series & 6 \\
\hline 11 & Guangming Ye(16) & China (Wuhan) & $40 \%$ & $32,27-42$ & Case-series & 5 \\
\hline 12 & Guo-Qing Qian(17) & China (Ningbo) & $41 \%$ & $50,5-96$ & Case-series & 91 \\
\hline 13 & Harrison X. Bai(18) & China (Changsha) & NS* & NS & cohort & 256 \\
\hline 14 & Heshui Shi(19) & China (Wuhan) & $52 \%$ & $49.5,39-61$ & Case-series & 81 \\
\hline 15 & Huanhuan Liu(20) & China (Shanghai) & $14 \%$ & $\begin{array}{c}20 \text { (2month-58 } \\
\text { yr) }\end{array}$ & Case-series & 51 \\
\hline 16 & Huijun Chen(21) & China (Wuhan) & $0 \%$ & $30,26-40$ & Case-series & 9 \\
\hline 17 & Jian Wu(22) & China (Yuncheng) & $49 \%$ & $46,4->65$ & Case-series & 80 \\
\hline 18 & Jianhua Xia MM(23) & China (Zhejiang) & $70 \%$ & $54.5,13-74$ & Cross-sectional & 30 \\
\hline 19 & KC Liu(24) & China (Hefei) & $51 \%$ & $42,5-86$ & Cohort & 73 \\
\hline 20 & Li Guo(25) & China (Beijing) & $50 \%$ & $35,2-64$ & Cross-sectional & 6 \\
\hline 21 & Li Yuanyuan(26) & China (Wuhan) & $46 \%$ & $52,25-82$ & Cross-sectional & 54 \\
\hline 22 & Lia Na Ji(27) & China (Beijing) & NS & NS & Case-series & 7 \\
\hline 23 & Lisi Deng(28) & china (Zhuha) & NS & $\geq 18$ year & Cohort & 56 \\
\hline 24 & Michael Chung(29) & $\begin{array}{c}\text { United States (New } \\
\text { York) }\end{array}$ & $61 \%$ & $51,29-77$ & Case-series & 21 \\
\hline 25 & Mingzhi Li(30) & China (Nanchang) & $55.5 \%$ & $43,31-68$ & Case-series & 9 \\
\hline 26 & Nanshan Chen(31) & China (Wuhan) & $68 \%$ & $21-821151$ & Case-series & 99 \\
\hline 27 & Rui Han(32) & China (Wuhan) & $35 \%$ & $45,21-95$ & Case-series & 108 \\
\hline 28 & Shuchang Zhou(33) & China (Wuhan) & $63 \%$ & $53,30-77$ & Case-series & 118 \\
\hline 29 & Soon Ho Yoon(34) & Korea (Seoul) & $44 \%$ & 54 & Case-series & 9 \\
\hline 30 & Suxin Wan(35) & China (Chongqing) & $53 \%$ & $47,36-55$ & Cross-sectional & 135 \\
\hline 31 & Taо Ai(36) & China (Wuhan) & $46 \%$ & $51,2-95$ & Cross-sectional & 1014 \\
\hline 32 & Tao Lu(37) & China (Sichuan) & $20 \%$ & $52,41-62$ & Case-series & 5 \\
\hline
\end{tabular}

\begin{tabular}{|c|c|c|c|c|c|c|}
\hline 33 & Tianmin $\mathrm{Xu}(38)$ & China (Changzhou) & $49 \%$ & $42,24-65$ & Cohort & 51 \\
\hline 34 & Wanbo Zhu(39) & China (Hefei) & $48 \%$ & $40,27-53$ & Case-series & 116 \\
\hline 35 & Wang XF(40) & China (Shenzhen) & $41 \%$ & 9 & Case-series & 34 \\
\hline 36 & Wei Li(41) & China (Zhuhai) & $80 \%$ & 3(10month-6yr) & Case-series & 5 \\
\hline 37 & Wenjie Yang(42) & China (Shanghai) & $54 \%$ & 45 & Case-series & 149 \\
\hline 38 & Wu Jing (43) & China (Nanjing) & $40 \%$ & $52,25-80$ & Case-series & 130 \\
\hline 39 & $\mathrm{Xi} \mathrm{Xu(44)}$ & China (Guangzhou) & $43 \%$ & $50,18-86$ & Case-series & 90 \\
\hline 40 & Xiang Dong(45) & China (Wuhan) & $45 \%$ & $37(2-69)$ & Case-series & 11 \\
\hline 41 & Xiaoli Zhang(46) & China (Zhejiang) & $51 \%$ & 46 & Cross-sectional & 645 \\
\hline 42 & Xingzhi Xie(47) & China (Changsha) & NS & NS & Cross-sectional & 167 \\
\hline 43 & Xiong Zeng(48) & China (Changsha) & NS & NS & Cross-sectional & 47 \\
\hline 44 & Yicheng Fang(4) & China (Shanghai) & $57 \%$ & $45,39-55$ & Case-series & 51 \\
\hline 45 & Yueying Pan(49) & China (Wuhan) & $52 \%$ & 45 & Case-series & 63 \\
\hline 46 & Zenghui Cheng(50) & China (Shanghi) & NS & NS & Cross-sectional & 38 \\
\hline 47 & Zhang MQ(51) & China (Beijing) & $56 \%$ & $36,15-49$ & Case-series & 9 \\
\hline
\end{tabular}

*NS: not stated.

Therefore, based on this approach and by analyzing 26 articles that reported less than $100 \%$ sensitivity, summary sensitivity of CT compared to PCR $86 \%$ (95\% Cl: $83 \%-90 \%)$ and summary specificity of CT based on six articles $43 \%(95 \% \mathrm{Cl}: 26 \%-60 \%)$. sensitivity is ranging from $25 \%$ to $97 \%$ and specificity is $25 \%$ to $70 \%$ in included articles (figure $3-4)$. The PPV of CT was $67 \%(95 \% \mathrm{Cl}: 57 \%-78 \%$ ) and the negative predictive value was $84 \%$ (95\% Cl: $74 \%-95 \%)$. Variation of estimated numbers is $33 \%$ to $97 \%$ and $33 \%$ to $95 \%$ for PPV and NPV respectively (figures 5,6 ). The symmetry between the two sides of the 
funnel plot regression line indicates that the publication is not biased in these articles However, due to the large number of zeros in the FP and TN cells, it was possible to calculate the odds ratio for six studies, and the interpretation of this plot in our study should be done with caution (figure 7).

The table 2 set out 15 articles which the information of the first test was available (subsequent RT-PCR data were included if available). Moreover, the swabs should have been taken from sputum, nasopharyngeal, oropharyngeal, nose or throat (if a combination used, nasopharyngeal swab (if not available, throat swab) considered as the primary). The result of the first, second, third and fourth positive RT-PCR test and also information of patients who had negative result until the fourth test but considered as confirmed or most likely ill later according to more RT- PCR tests or examining other swabs, clinical manifestations, typical chest CT scan's features or developmental changes in the series of CT scans or mixture of prior methods.

Table 2: The number of positive test result in RT-PCR testing and the number of confirmed ones (ordered by total number of cases)

\begin{tabular}{|c|c|c|c|c|c|c|c|c|}
\hline N. & First author & $\begin{array}{l}\text { N. of } \\
\text { total } \\
\text { cases }\end{array}$ & $\begin{array}{l}\text { Number } \\
\text { of total } \\
\text { confirmed } \\
\text { patients }\end{array}$ & $\begin{array}{l}\text { N. of } \\
\text { patients } \\
\text { confirmed } \\
\text { with the } \\
\text { first RT-PCR } \\
\text { test } \\
\quad \text { (perc. 1) } \\
\end{array}$ & $\begin{array}{l}\text { N. of } \\
\text { patients } \\
\text { confirmed } \\
\text { with the } \\
\text { second RT- } \\
\text { PCR test } \\
\text { (perc. 2) }\end{array}$ & $\begin{array}{l}\text { N. of patients } \\
\text { confirmed with } \\
\text { the third RT- } \\
\text { PCR test } \\
\text { (perc. 3) }\end{array}$ & $\begin{array}{l}\text { N. of } \\
\text { patients } \\
\text { confirmed with } \\
\text { the } \\
\text { fourth RT- } \\
\text { PCR test } \\
\text { (perc. 4) }\end{array}$ & $\begin{array}{l}\text { N. of } \\
\text { Patients } \\
\text { confirmed } \\
\text { later (perc. } \\
\text { 5) }\end{array}$ \\
\hline 1 & Tao Ai(36) & 1014 & 909 & 343 (37.7\%) & $\begin{array}{c}205 \\
(22.6 \%) \\
\end{array}$ & $45(5 \%)$ & $\begin{array}{c}8 \\
(0.9 \%) \\
\end{array}$ & $\begin{array}{c}308 \\
(33.9 \%) \\
\end{array}$ \\
\hline 2 & $\begin{array}{l}\text { Xingzhi } \\
\text { Xie(47) }\end{array}$ & 167 & 167 & 162 (97\%) & $2(1.2 \%)$ & $2(1.2 \%)$ & $0(0 \%)$ & $1(0.6 \%)$ \\
\hline 3 & Jian Wu(22) & 80 & 80 & $41(51.2 \%)$ & 30 (37.5\%) & 9 (11.3\%) & $0(0 \%)$ & $0(0 \%)$ \\
\hline 4 & $\begin{array}{c}\mathrm{Li} \\
\text { Yuanyuan(52) }\end{array}$ & 54 & 54 & 31 (57\%) & -6 & - & - & $\begin{array}{c}23 \\
(42.6 \%) \\
\end{array}$ \\
\hline 5 & Yicheng & 51 & 51 & $36(70.6 \%)$ & 12 (23.6\%) & $2(7.8 \%)$ & $1(2 \%)$ & $0(0 \%)$ \\
\hline
\end{tabular}

\begin{tabular}{|c|c|c|c|c|c|c|c|}
\hline & Fang(4) & & & & & & \\
\hline 6 & Qing Chen(53) & 9 & $9(100 \%)$ & _ & _ & _ & $0(0 \%)$ \\
\hline 7 & Li-Na Ji(54) & 7 & $4(80 \%)$ & - & - & - & $1(20 \%)$ \\
\hline 8 & $\begin{array}{c}\text { Jasper Fuk- } \\
\text { Woo Chan (15) }\end{array}$ & 6 & $4(80 \%)$ & - & - & - & $1(20 \%)$ \\
\hline 9 & Wei Li(41) & 1 & $(80 \%) 4$ & $0(0 \%)$ & $0(0 \%)$ & $0(0 \%)$ & $1(20 \%)$ \\
\hline 10 & $\mathrm{Li} \mathrm{Ni(55)}$ & 3 & 1 (33.3\%) & $0(0 \%)$ & $0(0 \%)$ & _ & $2(66.7 \%)$ \\
\hline 11 & $\begin{array}{l}\text { Yuanzhe } \\
\text { Li(56) }\end{array}$ & 22 & $1(50 \%)$ & $1(50 \%)$ & - & - & $0(0 \%)$ \\
\hline 12 & $\begin{array}{l}\text { Wendong } \\
\text { Hao(57) }\end{array}$ & 1 & $0(0 \%)$ & $0(0 \%)$ & $0(0 \%)$ & $1(100 \%)$ & $0(0 \%)$ \\
\hline 13 & $\begin{array}{c}\text { Peikai } \\
\text { Huang(58) }\end{array}$ & 1 & $0(0 \%)$ & $0(0 \%)$ & $1(100 \%)$ & - & $100 \%$ \\
\hline 14 & Jinrong Qu(59) & 1 & $1(100 \%)$ & - & - & - & $0(0 \%)$ \\
\hline 15 & $\begin{array}{l}\text { Xavier Marchand- } \\
\text { Senécal(60) }\end{array}$ & 1 & $1(100 \%)$ & - & - & - & $0(0 \%)$ \\
\hline
\end{tabular}

1 number of primarily confirmed patients divided total confirmed patients.

2 number of secondary confirmed patients divided total confirmed patients. 
3 number of thirdly confirmed patients divided total confirmed patients.

4 number of fourthly confirmed patients divided total confirmed patients.

5 number of patients who were confirmed later divided total confirmed patients.

6 This means the test has not been conducted or reported.

The mean percentage of primarily confirmed patients divided total confirmed patients in the articles with more than 10 total confirmed patients (the first 5 articles included), is $62.7 \%$. This means among these 5 articles, RT-PCR test could diagnose $62.7 \%$ of the COVID-19 infected patients in the first test, among all confirmed patients a nd about $37.3 \%$ of infected patients couldn't be recognized in the first place by RTPCR test. Among these 5 articles, 4 included the exact information of further tests (number 1,2,3 and 5). In these for articles the mean percentage of secondary, thirdly and fourthly confirmed patients divided total confirmed patients is $21.2 \%, 6.3 \%, 0.7 \%$ retrospectively. Moreover, the percentage of the patients who were not diagnosed after 4 times of repeating test was $8.6 \%$ (in the previous 4 articles). The number and sequence of primers and probes could be influential on PCR sensitivity and specificity which were surveyed in table 3.

Table 3: Based on the the information illustrated in table 2, the primer and probe 's data is presented (ordered by total number of cases)

\begin{tabular}{|c|c|c|c|c|c|c|}
\hline $\mathbf{N}$ & $\begin{array}{c}\text { First } \\
\text { author }\end{array}$ & $\begin{array}{c}\text { Total N. } \\
\text { of cases }\end{array}$ & $\begin{array}{c}\text { N. of patients confirmed } \\
\text { with the first RT-PCR test }\end{array}$ & $\begin{array}{c}\text { N. patients } \\
\text { confirmed } \\
\text { later }\end{array}$ & $\begin{array}{c}\text { primarily confirmed patients } \\
\text { divided total confirmed } \\
\text { patients (\%) }\end{array}$ & $\begin{array}{c}\text { Target } \\
\text { genes }\end{array}$ \\
\hline 1 & $\begin{array}{c}\text { Jian } \\
\text { Wu(22) }\end{array}$ & 80 & 41 & 39 & $51.2 \%$ & $\begin{array}{c}\text { N and } \\
\text { ORF1ab }\end{array}$ \\
\hline 2 & $\begin{array}{c}\text { Qing } \\
\text { Chen(53) }\end{array}$ & 9 & 9 & 0 & $100 \%$ & $\begin{array}{c}\text { RdRP, E and } \\
\text { N }\end{array}$ \\
\hline
\end{tabular}

\begin{tabular}{|c|c|r|l|r|r|c|}
\hline 3 & $\begin{array}{c}\text { Jasper Fuk- } \\
\text { Woo Chan (15) }\end{array}$ & 6 & 1 & $80 \%$ & RdRP and S \\
\hline 4 & $\begin{array}{c}\text { Wendong } \\
\text { Hao(57) }\end{array}$ & 1 & 0 & 1 & $0 \%$ & ORF1ab \\
\hline 5 & $\begin{array}{c}\text { Xavier Marchand- } \\
\text { Senécal(60) }\end{array}$ & 1 & 1 & 0 & $100 \%$ & RdRP \\
\hline
\end{tabular}

As we can see in table 3, in the case report by Wendong Hao (57), consuming one pair of primer and probe did not indicate positive result at first but in the fourth time. On the other hand, Xavier MarchandSenécal et al. reported a case that was diagnosed initially with one pair primer and probe PCR test. By using 2 pairs of primer and probe, the mean of initially detecting patients divided total confirmed patients, was $65.5 \%$. In addition, Qing Chen (53) findings implied utilization of 3 pair of primer and probe caused $100 \%$ of initially discovering COVID-19 patients (53). Based on limited data that has been found, totally, it seems that the more number of primer and probe have been used, the more initially detected patients have been achieved. Although more specific information is needed and demanded from future researchers to determine the exact desired conclusion. 


\section{Discussion}

Considering the outcomes of RT-PCR as reference, in our meta-analysis, the sensitivity and specificity of initial chest CT scan for detecting patients, who were highly suspicious for nCoV, were $86 \%$ and $43 \%$ respectively. The positive predictive value and negative predictive value of CT scan were $67 \%$ and $84 \%$ respectively. In a boarder sense, $67 \%$ of individuals with positive chest CT scan had positive RT-PCR and $84 \%$ of individuals with negative chest CT scan had negative RT-PCR. Despite numerous studies have been conducted on various subjects of $\mathrm{nCoV}$, the early diagnosis of patients who were infected with $\mathrm{nCoV}$ and also, suitable quarantine of them are under the debate. In accordance with previous studies, chest CT scan when it compares to RT-PCR, may have a variety of beneficial features including, but not limited to, less time-consuming and more availability, that makes doctors to take it into consideration as an adjuvant diagnostic tool $(61,62)$.

Tao Ai and his colleagues performed a study on 1014 patients and $888(88 \%)$ of them had positive chest CT scan and 601 patients had positive RT-PCR for nCoV, and the sensitivity, specificity, PPV, and NPV of CT scan were about $97 \%, 25 \%, 65 \%$, and $83 \%$ respectively that compare to our result sensitivity and specificity were much different. The possible reason behind relatively high sensitivity and low specificity in this study is the odds ratio of positive RT-PCR was low, which was considered as the reference (61).

There have been a number of patients with typical chest CT scan findings and symptoms for nCoV that their initial RT-PCR results were negative according to previous literatures $(4,18,61)$. For instance, following Y Fang et.al., study that showed that the result of initial RT-PCR in 15 out of 51 patients were negative while their chest CT scan were positive $(4,47,61)$. Hence, negative result of RT-PCR is not able to roll out $\mathrm{nCoV}$ and it is very important to pay attention to chest $\mathrm{CT}$ scan, epidemiologic features, and clinical symptoms. Diagnostic approach with favorably sensitivity and specificity is needed to control the rapid distribution of this disease. Therefore RT-PCR is suggested as a method for diagnosis of SARSCoV-2 by World Health Organization (WHO) (63). The swabs are commonly taken from sputum, nasopharyngeal, pharyngeal and throat which were included in our meta-analysis. Although WHO recommends examining stool specimens, together with nasopharyngeal swabs (63). Furthermore, combination of humoral and cellular immunity, for instance IgG-IgM antibody, alongside RT-PCR could possibly refine the detection of COVID-19 $(25,68)$.

According to Chen W., and his colleagues research, positive results based on blood samples, represent deterioration of the disease. Additionally, positive results of anal swabs are related to the severe phase of the disease and the RNA load was higher in anal swabs indicates that the virus may replicate in the digestive system (53). Stool swabs were positive in 8 out of 9 confirmed patients but urine and blood samples were negative in all (8). Also, plasma and urine samples caused negative result in the study by Jasper Chan et al, as well (15). A prospective case series including 30 confirmed COVID-19 patients (21 common type, 9 severe type and one of them had conjunctivitis) underwent RT-PCR test for both tear and conjunctival secretions specimens. Surprisingly, the results of the two specimens were positive the only conjunctivitis patient and the other 58 samples were negative. Therefore, tear and conjunctival secretions 
samples could possibly yield result for RT-PCR test in COVID-19 infected patients with conjunctivitis(23). Based on distinctly targeted genomes, the sensitivity of RT-PCR would be various. The results of Chan et al indicated that among 273 specimens from 15 positive COVID- 19 patients, RdRp-P2 test showed 77 positive specimens and RdRp/Hel test showed 42 positives, more and revealed RdRp/Hel assay has higher sensitivity. Moreover, RdRp/Hel analysis did not cross reacted with any human coronaviruses or other respiratory pathogens while RdRp-P2 analysis reacted to SARS-CoV, either (64). Another study expressed that the sensitivity of $\mathrm{N}$ gene assay in finding the positive samples, is 10 times more than ORF-1b gene assay(65).

In February, 280 suspected patients with clinical manifestations were enrolled in a hospital in Marseille, RT-PCR assay was conducted. About $51 \%$ of the patients were negative for all the common viruses, additionally none of the patients were positive for SARS-COV-2 (66). As reported by Guo-Qing Qian et al. 88 out of 91 suspected patients, were confirmed at least one time by RT-PCR assay in 2 sequential tests with 24 hour interval, and 3 patients with negative outcome reported as confirmed due to clinical manifestation (17). In the study by Tao Ai et al (N.1 in the table), from total 1014 patients, 601 patients were confirmed by Positive RT-PCR test and 308 patients with negative results were strongly perceived infected by clinical manifestations and CT scans approval. From total 909 patients, the percent of positive first, second, third and fourth test were $37.7 \%, 22.6 \%, 5 \%$, and $0.9 \%$, retrospectively. Additionally, about $33.9 \%$ of the patients could not be diagnosed with four repeating tests. Whereas CT scans were positive in 580 of 601 (97\%) confirmed RT-PCR test and 308 in 413(74.6\%) patients with negative RT-PCR assay, as well(36). On the report of Xingzhi Xie (N.2), from total 167 patients, 162 patients were confirmed by the first test ( 7 of them had normal CT), while 4 patients turned positive after the second and third test and the other patients became positive after multiple tests. Whereas all these patients had clinical symptoms in addition to GGO pattern on their CT scans(47). In the third study, more than two-thirds of the patients had abnormal CT scans(22). In a retrospective analysis(N.5), in the group of 51 patients, $98 \%$ (50/51) had abnormal CT, besides $70.6 \%(36 / 51)$ had positive PCR assay, initially, about $30 \%$ of the tests became positive after second, third and fourth scanning(4). from the report of a family cluster (N.7), 4 patients were confirmed by RT- PCR, one patients with negative PCR had GGO patterns in her CT and the other two with the same test result, had mild cough and fever for few days(54). On the report of 5 children (N.9), 4 of them had positive PCR outcome within first assay but one with CT findings turned positive after six times of examining (41). As specified by Li Ni (N.10), from 3 suspected patients, 2 patients showed negative PCR result after 3 repeated tests in 11 days and finally affirmed to be infected by typical CT features and clinical manifestations (55). On a report of 2 children, one of them had positive and the other had negative RT-PCR result which became positive in the day after, and at the same time, both had CT symptoms (56). In a case report represented a 56 years old man (N.12), RT-PCR assay was negative for 3 times and the fourth time became positive while CT demonstrated typical features such as groundglass opacification (GGO) (57). Another case report(N.13) presented a patient with negative PCR result but typical features of COVID-19 in CT. finally RT-PCR result became positive in the third examination (58). 
What stands out from table 2 is that, $62.7 \%$ of the infected COVIED-19 patients could be recognized in the first test and about $21.2 \%, 6.3 \%, 0.7 \%$ could be diagnosed in the further second, third and fourth tests, retrospectively. Actually, about $9 \%$ of the infected patients have not been detected, even after the fourth test. According to the results and due to the PCR's cost and time consumption, it seems repeating the test for 3 times is reasonable in patients with initially negative results (with 24hrs to 3 days' time interval based on literatures).

In fact about forth/ fifth of infected patients with COVID-19 virus have mostly mild and just about $15 \%$ of them may have severe ones. Usually patients who have the worse clinical symptoms like fever, dry cough, and low saturation are candidate for RT-PCR testing. Positive RT-PCR results usually have high positive predictive value, but negative RT-PCR should be repeated for three times in order to increase the negative predictive value equal to $98 \%$ (57\% first test, $34 \%$ second one, and $7 \%$ third times). If the patient's death is due to Covid-19 but their PCR indicated to the negative presence of virus and their chest CT is positive no death as the result of Covid-19 is reported. In fact, some patient with negative PCR result dies, but based on our results, $86 \%$ of them are covid positive and their disease should be confirmed by repeating PCR for three times. So the exact place of chest CT is staging the COVID-19 disease as the mild, moderate, and severe, but not screening and diagnosis of the disease. Serological tests can complement the PCR results because the negative value of chest CT can be due to the early stages of the disease. So PCR does not compete with chest CT but is used as a supplementary test.

We acknowledge that our study had some limitations: 1 . the specificity of CT scan was not as reliable as the sensitivity of that as a result of the majority of studies' nature, which were case- series and the number of true negative patients in those studies were zero. 2 it has been postulated in A Bernheim et al's study that chance of detecting lung involvement in chest CT scan will be increased if the duration between symptom onset and initial chest CT scan rises and this duration was different among 47 studies. So, the different outcomes would have emerged if the duration between studies were equal.

\section{Declarations}

Availability of data and material: Information, data, and photos will be provided if they requested.

Competing interests: All authors claim that there is not any potential competing or conflict of interest Funding: There is no funding.

Authors' contributions: SMK. A. was the principal investigator and supervisor of the project.M. S. was the epidemiologist who runs the statistical analysis of data and provides figures. SS.TZ and SZ. A. individually screened the data and make the data extraction sheet and tables of the article. F. KH had design the search strategy and wrote the manuscript. AN.SH edited the manuscript and co-supervised the project.

\section{References}


1. Bernheim A, Mei X, Huang M, Yang Y, Fayad ZA, Zhang N, et al. Chest CT Findings in Coronavirus Disease-19 (COVID-19): Relationship to Duration of Infection. Radiology. 2020:200463.

2. Mahase E. Covid-19: WHO declares pandemic because of "alarming levels" of spread, severity, and inaction. British Medical Journal Publishing Group;

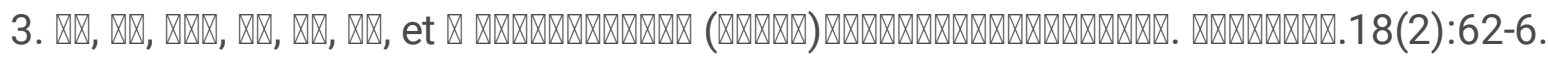

4. Fang Y, Zhang H, Xie J, Lin M, Ying L, Pang P, et al. Sensitivity of Chest CT for COVID-19: Comparison to RT-PCR. Radiology. 2020:200432.

5. Yang Y, Yang M, Shen C, Wang F, Yuan J, Li J, et al. Laboratory diagnosis and monitoring the viral shedding of 2019-nCoV infections. medRxiv.

6. Young BE, Ong SWX, Kalimuddin S, Low JG, Tan SY, Loh J, et al. Epidemiologic Features and Clinical Course of Patients Infected With SARS-CoV-2 in Singapore. Jama.

7. Guan CS, Lv ZB, Yan S, Du YN, Chen H, Wei LG, et al. Imaging Features of Coronavirus disease 2019 (COVID-19): Evaluation on Thin-Section CT. Academic radiology.

8. Xie C, Jiang L, Huang G, Pu H, Gong B, Lin H, et al. Comparison of different samples for 2019 novel coronavirus detection by nucleic acid amplification tests. Int $\mathrm{J}$ Infect Dis.

9. Zhao D, Yao F, Wang L, Zheng L, Gao Y, Ye J, et al. A comparative study on the clinical features of COVID-19 pneumonia to other pneumonias. Clinical infectious diseases : an official publication of the Infectious Diseases Society of America.

10. Liu D, Li L, Wu X, Zheng D, Wang J, Yang L, et al. Pregnancy and Perinatal Outcomes of Women With Coronavirus Disease (COVID-19) Pneumonia: A Preliminary Analysis. AJR American journal of roentgenology. 2020:1-6.

11. Zheng F, Liao C, Fan QH, Chen HB, Zhao XG, Xie ZG, et al. Clinical Characteristics of Children with Coronavirus Disease 2019 in Hubei, China. Current medical science.

12. Song F, Shi N, Shan F, Zhang Z, Shen J, Lu H, et al. Emerging Coronavirus 2019-nCoV Pneumonia. Radiology. 2020:200274.

13. Pan F, Ye T, Sun P, Gui S, Liang B, Li L, et al. Time Course of Lung Changes On Chest CT During Recovery From 2019 Novel Coronavirus (COVID-19) Pneumonia. Radiology. 2020:200370.

14. Feng K, Yun YX, Wang XF, Yang GD, Zheng YJ, Lin CM, et al. [Analysis of CT features of 15 Children with 2019 novel coronavirus infection]. Zhonghua Er Ke Za Zhi. 2020;58(0):E007.

15. Chan JF, Yuan S, Kok KH, To KK, Chu H, Yang J, et al. A familial cluster of pneumonia associated with the 2019 novel coronavirus indicating person-to-person transmission: a study of a family cluster. Lancet. 2020;395(10223):514-23.

16. Ye G, Pan Z, Pan Y, Deng Q, Chen L, Li J, et al. Clinical characteristics of severe acute respiratory syndrome coronavirus 2 reactivation. The Journal of infection.

17. Qian GQ, Yang NB, Ding F, Ma AHY, Wang ZY, Shen YF, et al. Epidemiologic and Clinical Characteristics of 91 Hospitalized Patients with COVID-19 in Zhejiang, China: A retrospective, multicentre case series. QJM : monthly journal of the Association of Physicians. 
18. Bai HX, Hsieh B, Xiong Z, Halsey K, Choi JW, Tran TML, et al. Performance of radiologists in differentiating COVID-19 from viral pneumonia on chest CT. Radiology. 2020:200823.

19. Shi H, Han X, Jiang N, Cao Y, Alwalid O, Gu J, et al. Radiological findings from 81 patients with COVID- 19 pneumonia in Wuhan, China: a descriptive study. Lancet Infect Dis.

20. Liu H, Liu F, Li J, Zhang T, Wang D, Lan W. Clinical and CT imaging features of the COVID-19 pneumonia: Focus on pregnant women and children. The Journal of infection.

21. Chen H, Guo J, Wang C, Luo F, Yu X, Zhang W, et al. Clinical characteristics and intrauterine vertical transmission potential of COVID-19 infection in nine pregnant women: a retrospective review of medical records. The Lancet.

22. Wu J, Liu J, Zhao X, Liu C, Wang W, Wang D, et al. Clinical Characteristics of Imported Cases of COVID-19 in Jiangsu Province: A Multicenter Descriptive Study. Clin Infect Dis.

23. Xia J, Tong J, Liu M, Shen Y, Guo D. Evaluation of coronavirus in tears and conjunctival secretions of patients with SARS-CoV-2 infection. J Med Virol. 2020.

24. Liu KC, Xu P, Lv WF, Qiu XH, Yao JL, Gu JF, et al. CT manifestations of coronavirus disease-2019: A retrospective analysis of 73 cases by disease severity. European journal of radiology. 2020;126:108941.

25. Guo L, Ren L, Yang S, Xiao M, Chang, Yang F, et al. Profiling Early Humoral Response to Diagnose Novel Coronavirus Disease (COVID-19). Clinical infectious diseases : an official publication of the Infectious Diseases Society of America.

26. Wang LS, Wang YR, Ye DW, Liu QQ. A review of the 2019 Novel Coronavirus (COVID-19) based on current evidence. International journal of antimicrobial agents. 2020:105948.

27. Ji LN, Chao S, Wang YJ, Li XJ, Mu XD, Lin MG, et al. Clinical features of pediatric patients with COVID-19: a report of two family cluster cases. World journal of pediatrics : WJP.

28. Deng L, Li C, Zeng Q, Liu X, Li X, Zhang H, et al. Arbidol combined with LPV/r versus LPV/r alone against Corona Virus Disease 2019: A retrospective cohort study. The Journal of infection.

29. Chung M, Bernheim A, Mei X, Zhang N, Huang M, Zeng X, et al. CT Imaging Features of 2019 Novel Coronavirus (2019-nCoV). Radiology. 2020:200230.

30. Li M, Lei P, Zeng B, Li Z, Yu P, Fan B, et al. Coronavirus Disease (COVID-19): Spectrum of CT Findings and Temporal Progression of the Disease. Academic radiology.

31. Chen N, Zhou M, Dong X, Qu J, Gong F, Han Y, et al. Epidemiological and clinical characteristics of 99 cases of 2019 novel coronavirus pneumonia in Wuhan, China: a descriptive study. Lancet. 2020;395(10223):507-13.

32. Han R, Huang L, Jiang H, Dong J, Peng H, Zhang D. Early Clinical and CT Manifestations of Coronavirus Disease 2019 (COVID-19) Pneumonia. AJR American journal of roentgenology. 2020:16.

33. Zhou S, Wang Y, Zhu T, Xia L. CT Features of Coronavirus Disease 2019 (COVID-19) Pneumonia in 62 Patients in Wuhan, China. AJR Am J Roentgenol. 2020:1-8. 
34. Yoon SH, Lee KH, Kim JY, Lee YK, Ko H, Kim KH, et al. Chest Radiographic and CT Findings of the 2019 Novel Coronavirus Disease (COVID-19): Analysis of Nine Patients Treated in Korea. Korean J Radiol.

35. Wan S, Xiang Y, Fang W, Zheng Y, Li B, Hu Y, et al. Clinical Features and Treatment of COVID-19 Patients in Northeast Chongqing. Journal of medical virology.

36. Stranieri A, Probo M, Pisu MC, Fioletti A, Meazzi S, Gelain ME, et al. Preliminary investigation on feline coronavirus presence in the reproductive tract of the tom cat as a potential route of viral transmission. J Feline Med Surg. 2020;22(2):178-85.

37. Lu T, Pu H. Computed Tomography Manifestations of 5 Cases of the Novel Coronavirus Disease 2019 (COVID-19) Pneumonia From Patients Outside Wuhan. Journal of thoracic imaging.

38. Xu T, Chen C, Zhu Z, Cui M, Chen C, Dai H, et Clinical features and dynamics of viral load in imported and non-imported patients with COVID-19. International journal of infectious diseases : IJID : official publication of the International Society for Infectious Diseases. 2020.

39. Zhu W, Xie K, Lu H, Xu L, Zhou S, Fang S. Initial clinical features of suspected coronavirus disease 2019 in two emergency departments outside of Hubei, China. Journal of medical virology.

40. Wang XF, Yuan J, Zheng YJ, Chen J, Bao YM, Wang YR, et al. Clinical and epidemiological characteristics of 34 children with 2019 novel coronavirus infection in Shenzhen. Zhonghua er ke za zhi $=$ Chinese journal of pediatrics. 2020;58:E008.

41. Li W, Cui H, Li K, Fang Y, Li S. Chest computed tomography in children with COVID-19 respiratory infection. Pediatric radiology.

42. Yang W, Cao Q, Qin L, Wang X, Cheng Z, Pan A, et al. Clinical characteristics and imaging manifestations of the 2019 novel coronavirus disease (COVID-19):A multi-center study in Wenzhou city, Zhejiang, China. J Infect.

43. Wu J, Feng CL, Xian XY, Qiang J, Zhang J, Mao QX, et [Novel coronavirus pneumonia (COVID-19) CT distribution and sign features]. Zhonghua Jie He He Hu Xi Za Zhi. 2020;43(0):E030.

44. Xu X, Yu C, Qu J, Zhang L, Jiang S, Huang D, et al. Imaging and clinical features of patients with 2019 novel coronavirus SARS-CoV-2. Eur J Nucl Med Mol Imaging. 2020.

45. Dong X, Cao YY, Lu XX, Zhang JJ, Du H, Yan YQ, et al. Eleven Faces of Coronavirus Disease 2019. Allergy.

46. Zhang X, Cai H, Hu J, Lian J, Gu J, Zhang S, et al. Epidemiological, clinical characteristics of cases of SARS-CoV-2 infection with abnormal imaging findings. International journal of infectious diseases: IJID : official publication of the International Society for Infectious Diseases.

47. Xie X, Zhong Z, Zhao W, Zheng C, Wang F, Liu J. Chest CT for Typical 2019-nCoV Pneumonia: Relationship to Negative RT-PCR Testing. Radiology. 2020:200343.

48. Xiong Z, Fu L, Zhou H, Liu JK, Wang AM, Huang Y, et al. [Construction and evaluation of a novel diagnosis process for 2019-Corona Virus Disease]. Zhonghua yi xue za zhi. 2020;100(0):E019. 
49. Pan Y, Guan H, Zhou S, Wang Y, Li Q, Zhu T, et al. Initial CT findings and temporal changes in patients with the novel coronavirus pneumonia (2019-nCoV): a study of 63 patients in Wuhan, China. Eur Radiol.

50. Cheng Z, Lu Y, Cao Q, Qin L, Pan Z, Yan F, et al. Clinical Features and Chest CT Manifestations of Coronavirus Disease 2019 (COVID-19) in a Single-Center Study in Shanghai, China. AJR American journal of roentgenology. 2020:1-6.

51. Zhang MQ, Wang XH, Chen YL, Zhao KL, Cai YQ, An CL, et al. [Clinical features of 2019 novel coronavirus pneumonia in the early stage from a fever clinic in Beijing]. Zhonghua Jie He He Hu Xi Za Zhi. 2020;43(0):E013.

52. Li YY, Wang WN, Lei Y, Zhang B, Yang J, Hu JW, et al. [Comparison of the clinical characteristics between RNA positive and negative patients clinically diagnosed with 2019 novel coronavirus pneumonia]. Zhonghua Jie He He Hu Xi Za Zhi. 2020;43(0):E023.

53. Chen W, Lan Y, Yuan X, Deng X, Li Y, Cai X, et al. Detectable 2019-nCoV viral RNA in blood is a strong indicator for the further clinical severity. Emerging Microbes and Infections. 2020;9(1):469-73.

54. Huang C, Wang Y, Li X, Ren L, Zhao J, Hu Y, et al. Clinical features of patients infected with 2019 novel coronavirus in Wuhan, China. The Lancet. 2020;395(10223):497-506.

55. Ni L, Zhou L, Zhou M, Zhao J, Wang DW. Combination of western medicine and Chinese traditional patent medicine in treating a family case of COVID-19 in Wuhan. Frontiers of medicine.

56. Li Y, Guo F, Cao Y, Li L, Guo Y. Insight into COVID-2019 for pediatricians. Pediatr Pulmonol.

57. Hao W, Li M. Clinical diagnostic value of CT imaging in COVID-19 with multiple negative RT-PCR testing. Travel medicine and infectious disease. 2020:101627.

58. Huang P, Liu T, Huang L, Liu H, Lei M, Xu W, et al. Use of Chest CT in Combination with Negative RTPCR Assay for the 2019 Novel Coronavirus but High Clinical Suspicion. Radiology. 2020:200330.

59. Qu J, Yang R, Song L, Kamel IR. Atypical lung feature on chest CT in a lung adenocarcinoma cancer patient infected with COVID-19. Annals of oncology : official journal of the European Society for Medical Oncology.

60. Marchand-Senecal X, Kozak R, Mubareka S, Salt N, Gubbay JB, Eshaghi A, et al. Diagnosis and Management of First Case of COVID-19 in Canada: Lessons applied from SARS. Clinical infectious diseases : an official publication of the Infectious Diseases Society of America.

61. Ai T, Yang Z, Hou H, Zhan C, Chen C, Lv W, et al. Correlation of Chest CT and RT-PCR Testing in Coronavirus Disease 2019 (COVID-19) in China: A Report of 1014 Cases. Radiology. 2020:200642.

62. Shiri I, Maleki H, Hajianfar G, Abdollahi H, Ashrafinia S, Hatt M, et al. Next-Generation Radiogenomics Sequencing for Prediction of EGFR and KRAS Mutation Status in NSCLC Patients Using Multimodal Imaging and Machine Learning Algorithms. Mol Imaging Biol.

63. World health organization(WHO)-Use of laboratory methods for SARS diagnosis(https://www.who.int/csr/sars/labmethods/en/) (access 2 April). 
64. Chan JF, Yip CC, To KK, Tang TH, Wong SC, Leung KH, et al. Improved molecular diagnosis of COVID19 by the novel, highly sensitive and specific COVID-19-RdRp/Hel real-time reverse transcriptionpolymerase chain reaction assay validated in vitro and with clinical specimens. J Clin Microbiol.

65. Chu DKW, Pan Y, Cheng SMS, Hui KPY, Krishnan P, Liu Y, et al. Molecular Diagnosis of a Novel Coronavirus (2019-nCoV) Causing an Outbreak of Pneumonia. Clin Chem.

66. Amrane S, Tissot-Dupont H, Doudier B, Eldin C, Hocquart M, Mailhe M, et al. Rapid viral diagnosis and ambulatory management of suspected COVID-19 cases presenting at the infectious diseases referral hospital in Marseille, France, - January 31st to March 1st, 2020: A respiratory virus snapshot. Travel medicine and infectious disease. 2020:101632.

67. Lei P, Fan B, Mao J, Wang P. Comprehensive analysis for diagnosis of novel coronavirus disease (COVID-19) infection. The Journal of infection. 2020.

68. Li Z, Yi Y, Luo X, Xiong N, Liu Y, Li S, et al. Development and Clinical Application of A Rapid IgM-IgG Combined Antibody Test for SARS-CoV-2 Infection Diagnosis. J Med Virol.

\section{Figures}




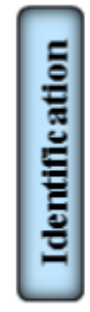

All identified document finding through search in Pubmed, Scopus, Embase $(n=667)$
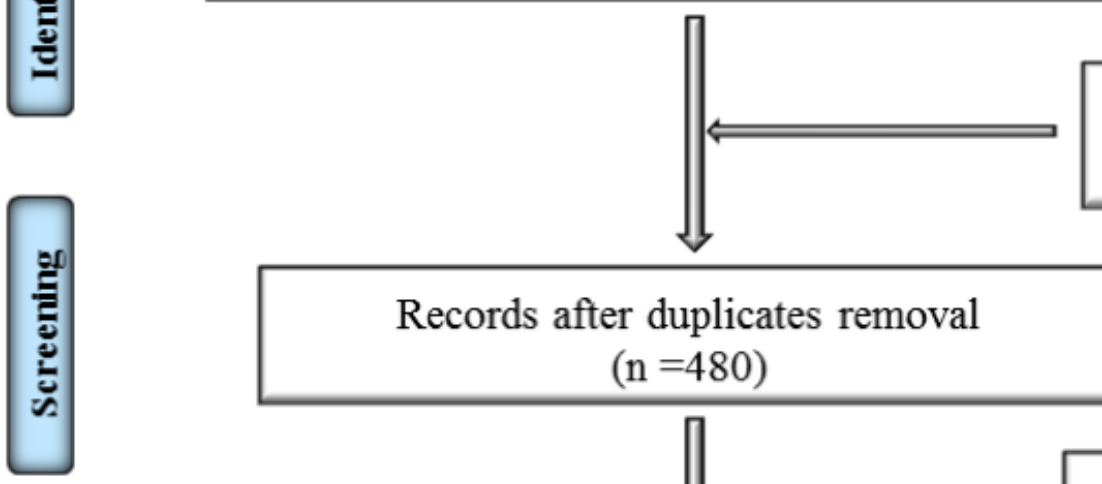

Additional records identified through other sources $(n=1)$

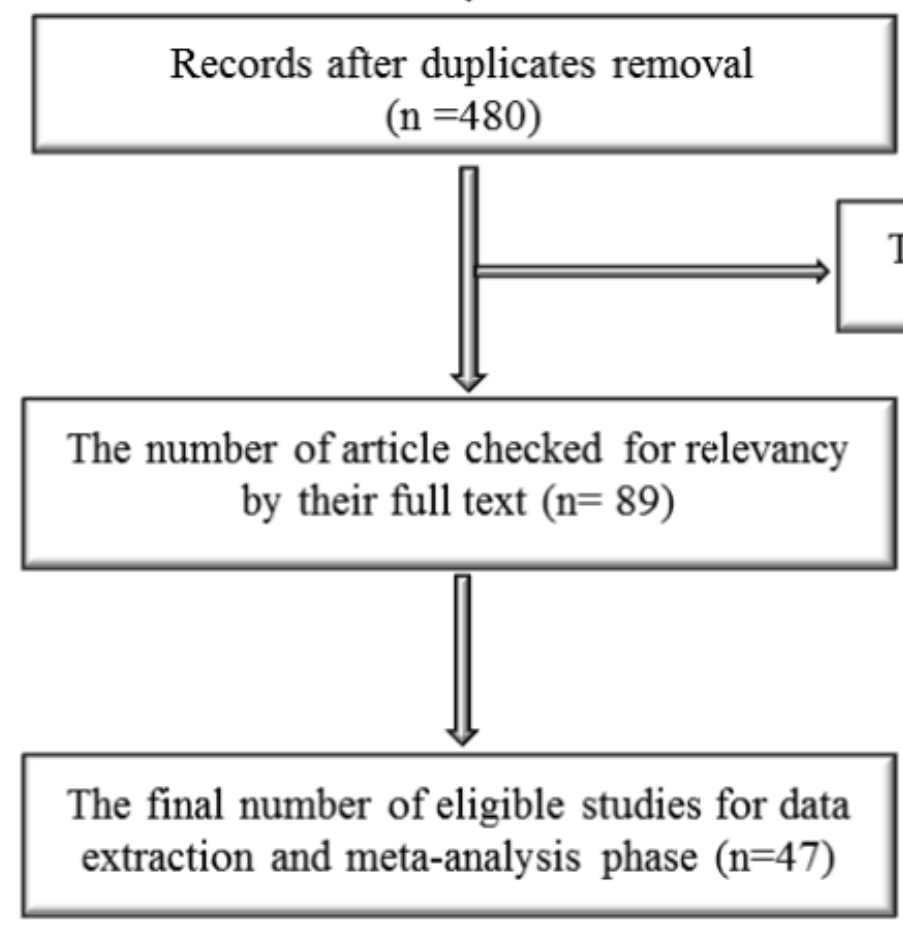

Figure 1

The number of article during several steps based on the PRISMA flow diagram (2009) 


\begin{tabular}{|c|c|c|c|c|c|c|}
\hline Study & TP & FP & FN & TN & Sensitivity & Specificity \\
\hline Adam Bernheim 2020 & 94 & 0 & 27 & 0 & $0.78[0.69,0.85]$ & Not estimable \\
\hline Chun Shuang Guan 2020 & 47 & 0 & 6 & 0 & $0.89[0.77,0.96]$ & Not estimable \\
\hline Chunbao Xie 2020 & 9 & 5 & 0 & 5 & $1.00[0.66,1.00]$ & $0.50[0.19,0.81]$ \\
\hline Dahai Zhao 2020 & 19 & 15 & 0 & 0 & $1.00[0.82,1.00]$ & $0.00[0.00,0.22]$ \\
\hline Dehan Liu 2020 & 15 & 0 & 0 & 0 & $1.00[0.78,1.00]$ & Not estimable \\
\hline Fang ZHENG 2020 & 17 & 0 & 8 & 0 & $0.68[0.46,0.85]$ & Not estimable \\
\hline Fenxiang Song 2020 & 51 & 0 & 0 & 0 & $1.00[0.93,1.00]$ & Not estimable \\
\hline Fneg Pang 2020 & 17 & 0 & 4 & 0 & $0.81[0.58,0.95]$ & Not estimable \\
\hline Freng K 2020 & 9 & 0 & 6 & 0 & $0.60[0.32,0.84]$ & Not estimable \\
\hline Fuk-Woo Chan 2020 & 5 & 1 & 0 & 1 & $1.00[0.48,1.00]$ & $0.50[0.01,0.99]$ \\
\hline Guangming Ye 2020 & 5 & 0 & 0 & 0 & $1.00[0.48,1.00]$ & Not estimable \\
\hline Guo-Qing Qian 2020 & 83 & 3 & 5 & 0 & $0.94[0.87,0.98]$ & $0.00[0.00,0.71]$ \\
\hline Harrison X. Bai 2020 & 219 & 0 & 37 & 0 & $0.86[0.81,0.90]$ & Not estimable \\
\hline Heshui Shi 2020 & 81 & 0 & 0 & 0 & $1.00[0.96,1.00]$ & Not estimable \\
\hline Huanhuan Liu 2020 & 30 & 17 & 4 & 0 & $0.88[0.73,0.97]$ & $0.00[0.00,0.20]$ \\
\hline Hujun Chen 2020 & 8 & 0 & 1 & 0 & $0.89[0.52,1.00]$ & Not estimable \\
\hline Jian Wu 2020 & 55 & 0 & 25 & 0 & $0.69[0.57,0.79]$ & Not estimable \\
\hline Jianhua Xia MM 2020 & 30 & 0 & 0 & 0 & $1.00[0.88,1.00]$ & Not estimable \\
\hline KC Liu 2020 & 70 & 0 & 3 & 0 & $0.96[0.88,0.99]$ & Not estimable \\
\hline Li Guo 2020 & 1 & 2 & 1 & 1 & $0.50[0.01,0.99]$ & $0.33[0.01,0.91]$ \\
\hline Li YY 2020 & 31 & 23 & 0 & 0 & $1.00[0.89,1.00]$ & $0.00[0$. \\
\hline Lia Na J 2020 & 1 & 1 & 3 & 2 & $0.25[0.01,0.81]$ & $0.67[0$. \\
\hline Lisi Deng 2020 & 37 & 0 & 19 & 0 & $0.66[0.52,0.78]$ & stimable \\
\hline Michael Chung 2020 & 18 & 0 & 3 & 0 & $0.86[0.64,0.97]$ & stimable \\
\hline Mingzhi Li 2020 & 9 & 0 & 0 & 0 & $1.00[0.6$ & stimable \\
\hline Nanshan Chen 2020 & 99 & 0 & 0 & 0 & $1.00[0.96,1.00]$ & Not estimable \\
\hline Rui Han 2020 & 108 & 0 & 0 & 0 & $1.00[0.97,1.00]$ & stimable \\
\hline Shuchang Zhou 2020 & 62 & 56 & 0 & 0 & $1.00[0.94,1.00]$ & $0.00[0.00,0.06]$ \\
\hline Soon Ho Yoon 2020 & 9 & 0 & 0 & 0 & $1.00[0.66,1.00]$ & \\
\hline Suxin Wan 2020 & 135 & 0 & 0 & 0 & $1.00[0.97,1.00]$ & Not estimable \\
\hline Tao Ai 2020 & 580 & 308 & 21 & 105 & $0.97[0.95,0.98]$ & $0.25[0.21,0.30]$ \\
\hline Tao Lu 2020 & 5 & 0 & 0 & 0 & $1.00[0.48,1.00]$ & Not estimable \\
\hline Tianmin Xu 2020 & 49 & 2 & 0 & 0 & $1.00[0.93,1.00]$ & $0.00[0.00,0.84]$ \\
\hline Wanbo Zhu 2020 & 30 & 56 & 2 & 28 & $0.94[0.79,0.99]$ & $0.33[0.23,0.44]$ \\
\hline Wang XF 2020 & 34 & 0 & 0 & 0 & $1.00[0.90,1.00]$ & Not estimable \\
\hline Wei Li 2020 & 2 & 1 & 2 & 0 & $0.50[0.07,0.93]$ & $0.00[0.00,0.97]$ \\
\hline Wenjie Yang 2020 & 132 & 0 & 17 & 0 & $0.89[0.82,0.93]$ & Not estimable \\
\hline Wu J 2020 & 130 & 0 & 0 & 0 & $1.00[0.97,1.00]$ & Not estimable \\
\hline XI Xu 2020 & 69 & 0 & 21 & 0 & $0.77[0.67,0.85]$ & Not estimable \\
\hline Xiang Dong 2020 & 7 & 1 & 2 & 1 & $0.78[0.40,0.97]$ & $0.50[0.01,0.99]$ \\
\hline Xiaol Zhang 2020 & 573 & 0 & 72 & 0 & $0.89[0.86,0.91]$ & Not estimable \\
\hline Xingzhi Xie 2020 & 155 & 5 & 7 & 0 & $0.96[0.91,0.98]$ & $0.00[0.00,0.52]$ \\
\hline XiongA zeng 2020 & 19 & 8 & 1 & 19 & $0.95[0.75,1.00]$ & $0.70[0.50,0.86]$ \\
\hline Yicheng Fang 2020 & 35 & 15 & 1 & 0 & $0.97[0.85,1.00]$ & $0.00[0.00,0.22]$ \\
\hline Yueying Pan 2020 & 63 & 0 & 0 & 0 & $1.00[0.94,1.00]$ & Not estimable \\
\hline Zenghui Cheng 2020 & 11 & 22 & 0 & 5 & $1.00[0.72,1.00]$ & $0.19[0.06,0.38]$ \\
\hline Zhang MQ 2020 & 7 & 0 & 2 & 0 & $0.78[0.40,0.97]$ & Not estimable \\
\hline
\end{tabular}

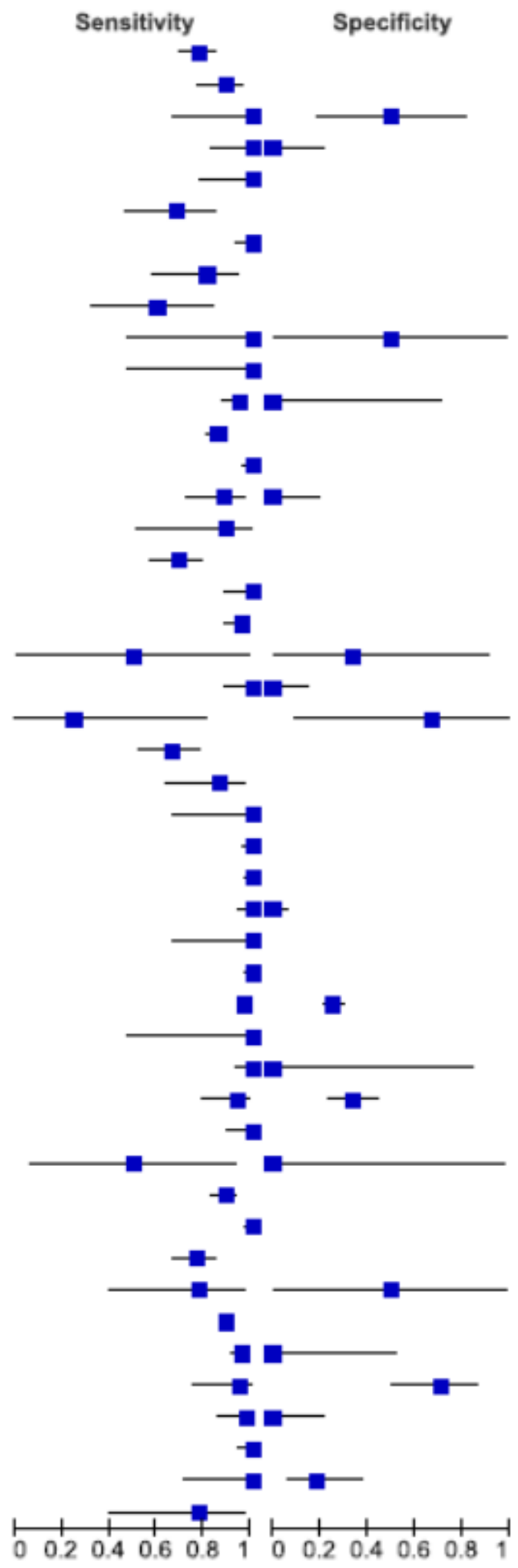

Figure 2

Sensitivity and specificity of 47 included studies 


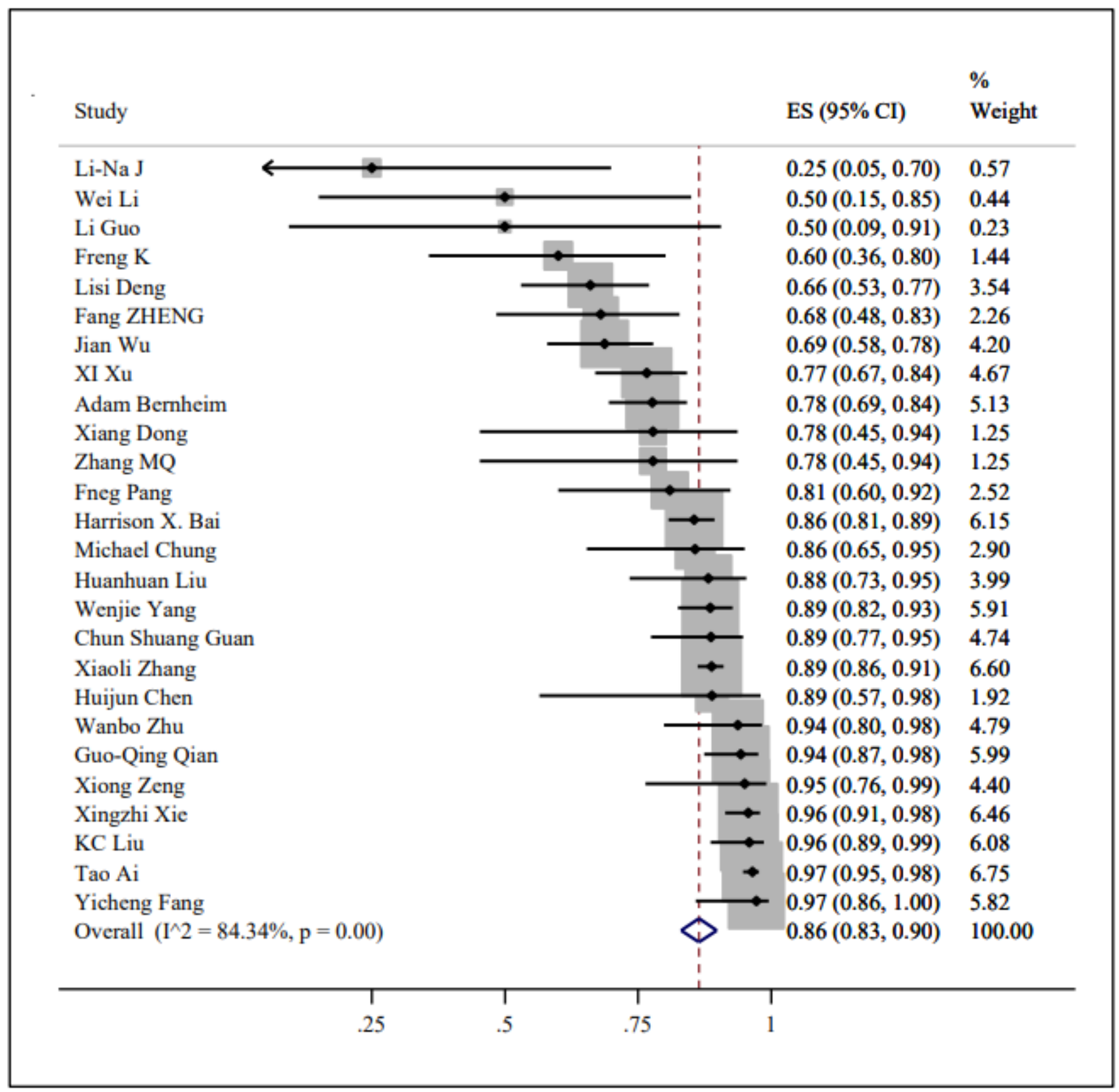

\section{Figure 3}

Summary of sensitivity and $95 \% \mathrm{Cl}$ of 26 study, generated by the STATA procedure metaprop 


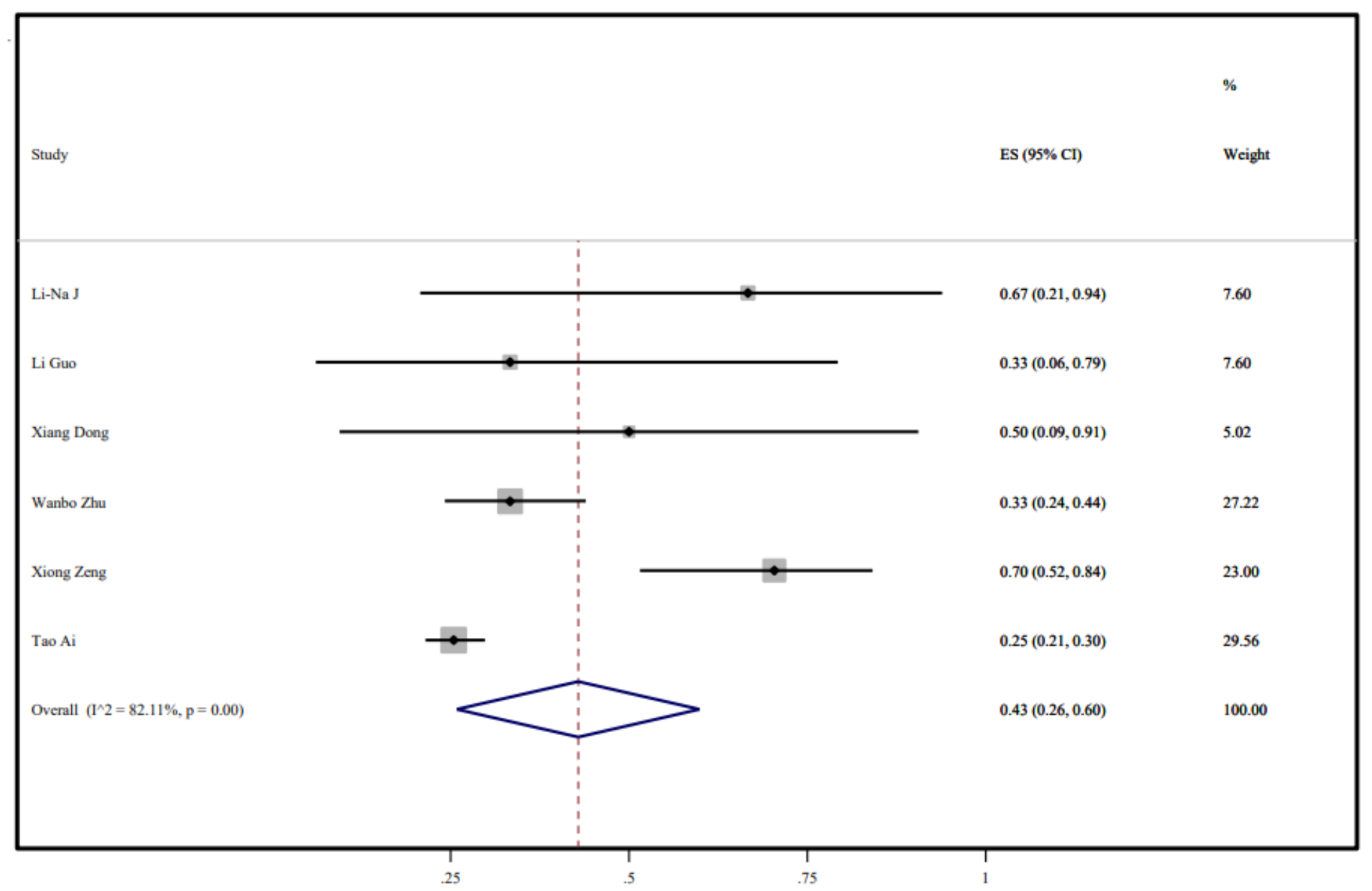

Figure 4

Summary of specificity and $95 \% \mathrm{Cl}$ of 6 study, generated by the STATA procedure metaprop 
Study

ES $(95 \% \mathrm{CI}) \quad$ Weight

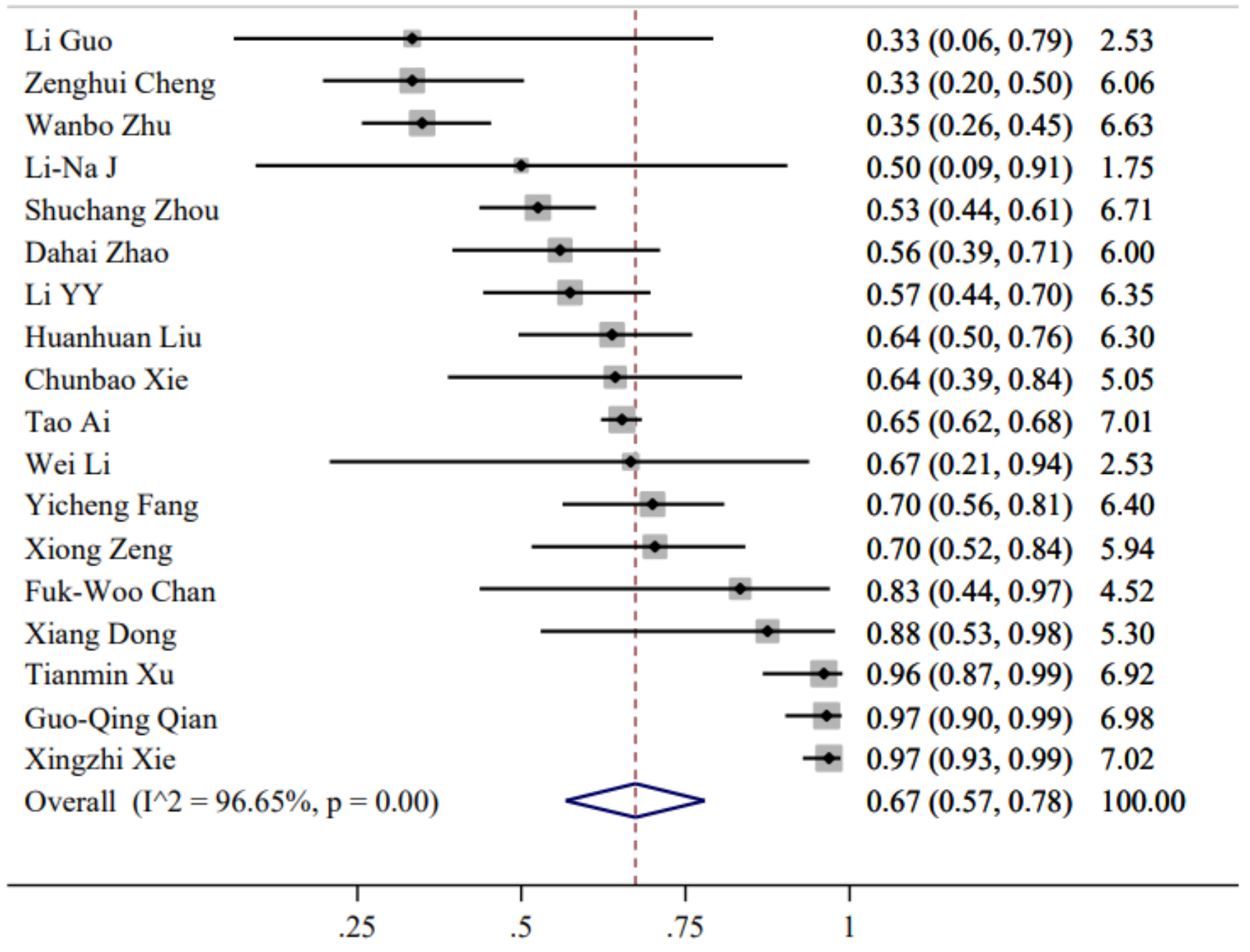

\section{Figure 5}

Summary of positive predictive value and $95 \% \mathrm{Cl}$ of 18 study, generated by the STATA procedure Metaprop 


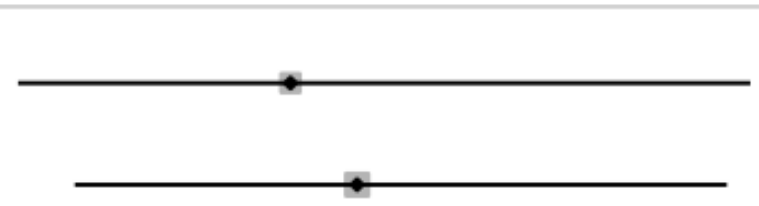

Li Guo

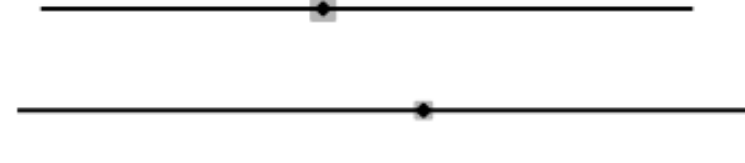

Tao Ai

Wanbo Zhu

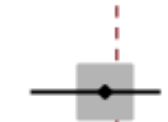

$0.50(0.09,0.91)$

2.33

$0.83(0.76,0.89)$

31.63

$0.93(0.79,0.98)$

28.79

Xiong Zeng

Overall $\left(\mathrm{I}^{\wedge} 2=67.47 \%, \mathrm{p}=0.01\right)$

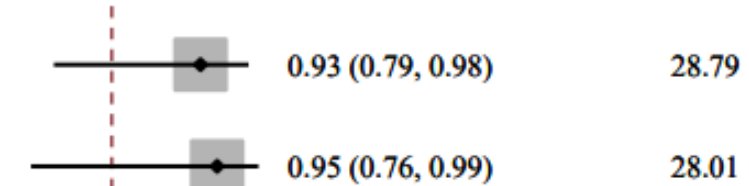

$0.84(0.74,0.95)$

100.00

\section{Figure 6}

Summary of negative predictive value and $95 \% \mathrm{Cl}$ of 6 study, generated by the STATA procedure Metaprop 


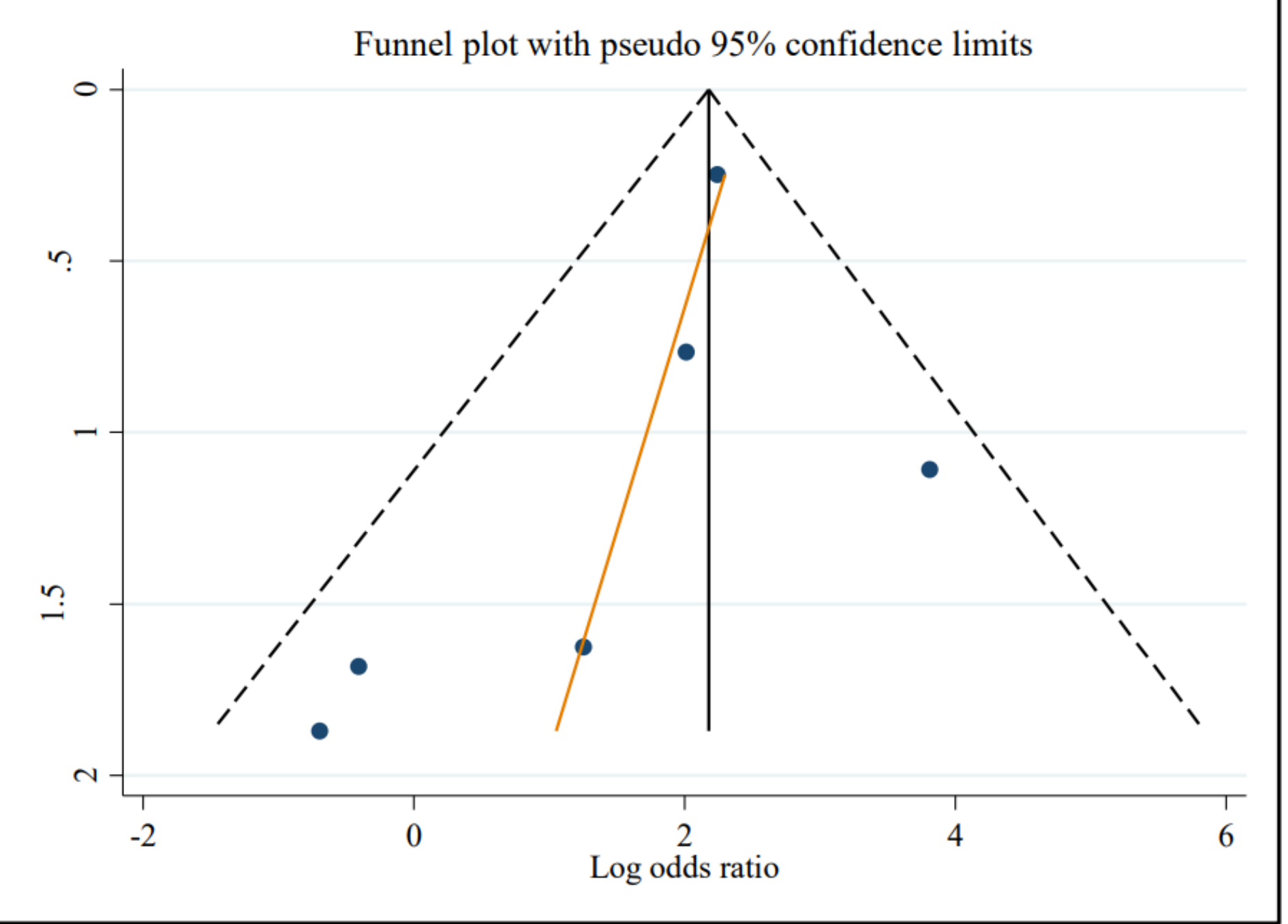

Figure 7

The Deeks' funnel plot curve for assessment of publication bias

\section{Supplementary Files}

This is a list of supplementary files associated with this preprint. Click to download.

- Supplementaryinformation.pdf

- CopyofDataExtractionSheet11.xlsx 